American J. of Engineering and Applied Sciences 3 (1): 232-239, 2010

ISSN 1941-7020

(C) 2010 Science Publications

\title{
A Review of Constitutive Models for Rubber-Like Materials
}

\author{
${ }^{1}$ Aidy Ali, ${ }^{1}$ M. Hosseini and ${ }^{1,2}$ B.B. Sahari \\ ${ }^{1}$ Department of Mechanical and Manufacturing Engineering, Faculty of Engineering, \\ University Putra Malaysia, UPM, 43400 Serdang, Selangor, Malaysia \\ ${ }^{2}$ Institute of Advanced Technology, University Putra Malaysia, \\ UPM, 43400 Serdang, Selangor, Malaysia
}

\begin{abstract}
Problem statement: This study reviewed the needs of different constitutive models for rubber like material undergone large elastic deformation. The constitutive models are widely used in Finite Element Analysis (FEA) packages for rubber components. Most of the starting point for modeling of various kinds of elastomer is a strain energy function. In order to define the hyperelastic material behavior, stress-strain response is required to determine material parameters in the strain energy potential and also proper selection of rubber elastic material model is the first attention. Conclusion: This review provided a sound basis decision to engineers and manufactures to choose the right model from several constitutive models based on strain energy potential for incompressible and isotropic materials.
\end{abstract}

Key words: Rubber, elastomer, hyperelastic, constitutive model

\section{INTRODUCTION}

Rubber material usually has long chain molecules recognized as polymers. The term elastomer is the combination of elastic and polymer and is often used interchangeably with the rubber (Smith, 1993). In recent years, rubber component as an engineering material has been used in many industries such as automotive and in a wide range of applications consist of engine mountings, tires, vibration isolators, medical devices and structural bearings. Rubber is an ideal material for many applications because it can withstand very large strains over $500 \%$ with no permanent deformation or fracture (Mars, 2002). Besides elastic recovery, elastomers have special physical properties (flexibility, extensibility, resiliency and durability), which are unmatched by other types of materials (Coran, 2006), however it still presents behavior in common with other material (Abraham et al., 2005). This notable characteristics change with diverse variable including fatigue, light, heat, oxygen and ozone, during passing of time (Nagdi, 1993).

Elastomers present a very complicated mechanical behavior that exceed the linear elastic theory and contain large deformations, plastic and viscoelastic properties and stress softening (Chagnon et al., 2004; Naser et al., 2005). Stress softening is known as the Mullins effect and happened during initial loading cycles. The residual strain are not accounted for when the mechanical properties of rubber are presented in terms of a strain energy function (Dorfmann and Ogden, 2004; Cheng and Chen, 2003). The Mullins effect is closely related to the fatigue of rubber components using in engineering applications and it can be considered as a necessary step for evaluation of the life of a rubber parts. There are many phenomenological theories to define the Mullins effect in literature (Horgan et al., 2004). The viscous and elastic components change with temperature and strain rate. These characteristics present complications to the modeling of elastomers compared with other traditional engineering materials (Whibley et al., 2005). Geometrical and different physical nonlinearities have to be taken into account in order to model rubber materials and nowadays, the finite element methods (FEM) is a powerful tool to analyze rubber components. Usually, these structures can not be defined analytically because of material nonlinearities and their complex geometry (Kaliske et al., 2001).

Elastomers are basically super-condensed gases because most primary monomers are gases and after polymerization have long chain molecules which will be in an amorphous (rubber), glassy or crystalline phase. During cross linking or vulcanization, rubber molecules are chemically fastened together at various points to form a network. They make stationary

Corresponding Author: Aidy Ali, Department of Mechanical and Manufacturing Engineering, Faculty of Engineering, University Putra Malaysia, UPM, 43400 Serdang, Selangor, Malaysia 
Am. J. Engg. \& Applied Sci., 3 (1): 232-239, 2010

positions to prevent slippage of chains. Figure 1 shows the tensile stress-strain diagram for three physical states of a polymer. A glassy polymer is brittle. A crystalline polymer pass sequence of changes consist of, elastic deformation, yield, plastic flow, necking, strain hardening and strain fracture. Rubbers are unique in being soft, very extensible and very elastic (Yan et al., 2005; Hertz, 1992; Yan and Strenskowski, 2006).

Rubber can be defined by a stored energy function as hyperelastic material. The coefficients in these functions should be determined by uniaxial, biaxial and shear test data. The essential problem is to determine the strain energy function for providing good fit with a number of sets of experiment data. The purpose of this review is to introduce the popular models which are available in numerical community and offered in the literature.

Elasticity: Rubber has long and flexible molecular structures which are the ability to stretch to several times its original length. By a simple assumption of linear stress-strain relationship, rubber can be considered as a linearly elastic material at small strains, like all solids and can be understood in many common rubber design problems. However for analyzing rubber behavior in large deformation, the large elastic deformation theory should be considered (Gent, 1992).

According to Rivlin's phenomenological theory, rubber is assumed isotropic in elastic behavior and very nearly incompressible. The elastic properties of a rubber can be explained in terms of a strain energy function based on the strain invariants $\mathrm{I}_{1}, \mathrm{I}_{2}$ and $\mathrm{I}_{3}$. This theory offers a mathematical framework to describe rubbery behavior based on continuum mechanics. In this approach, stress and strain analysis problems may be solved independent of the microscopic system or molecular concepts and the elasticity theory can be the starting point of any kind of modeling effort as follows (Boyce and Arruda, 2000; Achenbach and Duarte, 2003; Pucci and Saccomandi, 2002; Yeoh and Fleming, 1997; Chang et al., 1991):

$\mathrm{W}=\mathrm{f}\left(\mathrm{I}_{1}, \mathrm{I}_{2}, \mathrm{I}_{3}\right)$

Where:

$\mathrm{W}=$ Sometimes is written as $\mathrm{U}$ is the strain energy density or stored energy function defined per unit volume

$\mathrm{I}_{1}, \mathrm{I}_{2}$ and $\mathrm{I}_{3}=$ The three invariants of the green deformation tensor given in terms of the principle extension ratios $\lambda_{1}, \lambda_{1}$ and $\lambda_{3}$, by:

$\mathrm{I}_{1}=\lambda_{1}{ }^{2}+\lambda_{2}{ }^{2}+\lambda_{3}{ }^{2}$
$\mathrm{I}_{2}=\lambda_{1}{ }^{2} \lambda_{2}{ }^{2}+\lambda_{2}{ }^{2} \lambda_{3}{ }^{2}+\lambda_{3}{ }^{2} \lambda_{1}{ }^{2}$
$\mathrm{I}_{3}=\lambda_{1}{ }^{2} \lambda_{2}{ }^{2} \lambda_{3}{ }^{2}$

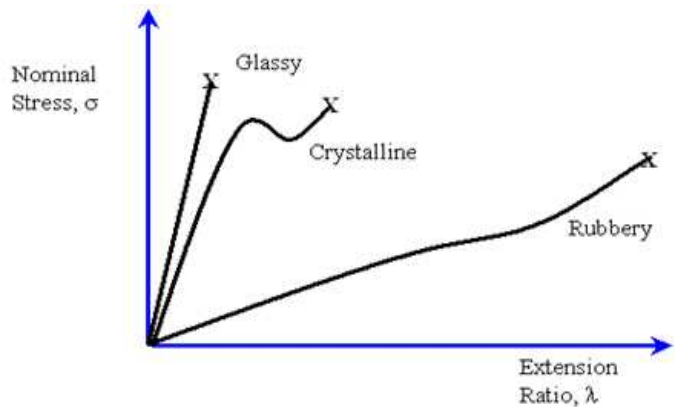

Fig. 1: Tensile stress-strain diagrams for polymers in three physical states; $x$ denotes rupture

Equation 1 can be represented as:

$\mathrm{W}=\sum_{\mathrm{i}+\mathrm{j}+\mathrm{k}=1}^{\infty} \mathrm{C}_{\mathrm{ijk}}\left(\mathrm{I}_{1}-3\right)^{\mathrm{i}} \cdot\left(\mathrm{I}_{2}-3\right)^{\mathrm{j}} \cdot\left(\mathrm{I}_{3}-1\right)^{\mathrm{k}}$

By considering that rubber is incompressible, for these materials $I_{3}=1$, thus Eq. 3 decreases to:

$\mathrm{W}=\sum_{\mathrm{i}+\mathrm{j}=1}^{\infty} \mathrm{C}_{\mathrm{ij}}\left(\mathrm{I}_{1}-3\right)^{\mathrm{i}} \cdot\left(\mathrm{I}_{2}-3\right)^{\mathrm{j}}$

Hyperelastic models: A considerable amount of literature has been published on modeling of rubber material. The choice of the model depends to its application, corresponding variables and its available data to determine material parameters. The validity of possible models should be studied and the simplest is selected with high accuracy and low materials parameters (Lemaitre, 2001).

The modeling and design of hyperelastic materials is the selection of a proper strain energy function $\mathrm{W}$, and accurate determination of material constants for function (Garcia Ruiz and Suarez Gonzalez, 2006). There are various forms of strain energy potentials for modeling of incompressible and isotropic elastomer (Ogden, 1972; Mars and Fatemi, 2004; Guo and Sluys, 2006; Selvadurai, 2006; Horgan and Saccomandi, 1999; 2003; Amin et al., 2002; Beatty, 2003; Meunier et al., 2008; Muhr 2005; Sasso et al., 2008). However, only some of them describe the complete behavior of these materials, especially, for different loading conditions with experimental data (Markmann and Verron, 2005; 2006).

An efficient hyperelastic model can be explained by four main qualities (Chagnon et al., 2004):

- It should have the ability to exactly reproduce the whole 'S' shaped response of rubbers 
- The change of deformation modes must not be problematic, i.e., if the model operates sufficiently in uniaxial tension, it must also be exact in simple shear or in equibiaxial tension

- The number of fitting material parameters should be small, in order to decrease the number of experimental tests for their determination

- The mathematical formulation should be simple display practicable for the numerical performance of the model

Five and six different models were compared for describing of the deformation behavior with experimental data by Boyce and Arruda (2000) and Seibert and Schoche (2000), respectively. In another study, Markmann and Verron (2006) compared twenty hyperelastic models for rubber-like materials and classified them with respect to their ability to fit experimental data. They reviewed hyperelastic models in three major categories including, phenomenological and empirical models, physical-based models, approaches in derivatives $\partial \mathbf{W} / \partial \mathbf{I}_{1}$ and $\partial \mathbf{W} / \partial \mathbf{I}_{2}$.

The statistical or kinetic theory attempts to derive stress-strain properties of rubber from some idealized model of its macromolecular structure and the phenomenological theory treats the problem based on continuum mechanics without reference to molecular concepts (Yeoh and Fleming, 1997).

Polynominal model: The polynomial model offered here in the compressible form, based on the 1st and the 2nd invariant $\overline{\mathrm{I}}_{1}$ and $\overline{\mathrm{I}}_{2}$ of the deviatoric Cauchy-Green tensor, that is:

$$
\mathrm{U}=\sum_{\mathrm{i}+\mathrm{j}=1}^{\mathrm{N}} \mathrm{C}_{\mathrm{ij}}\left(\overline{\mathrm{I}}_{1}-3\right)^{\mathrm{i}}\left(\overline{\mathrm{I}}_{2}-3\right)^{\mathrm{j}}+\sum_{\mathrm{i}=1}^{\mathrm{N}} \frac{1}{\mathrm{D}_{\mathrm{i}}}\left(\mathrm{J}_{\mathrm{el}}-1\right)^{2 \mathrm{i}}
$$

Where:

$\mathrm{U} \quad=$ The strain energy potential (or strain energy density), that is the strain per unit of reference volume

$\mathrm{J}_{\mathrm{el}}=$ The elastic volume ratio

$\overline{\mathrm{I}}_{1}$ and $\overline{\mathrm{I}}_{2}=$ The first and second invariants of the deviatoric strain,

$\mathrm{C}_{\mathrm{ij}}$ and $\mathrm{D}_{\mathrm{i}}=$ Material constant

$\mathrm{N}=\mathrm{A}$ positive determining the number of terms in the strain energy function $(\mathrm{N}=1,2,3)$

$\mathrm{C}_{\mathrm{ij}}=$ Describes the shear behavior of the material

$\mathrm{D}_{\mathrm{i}} \quad=$ Introduces compressibility and is set equal to zero for fully incompressible materials
This model of strain energy function is usually used in modeling the stress-strain behavior of filled elastomers, with four to five terms (Forni et al., 1999).

Reduced polynominal model: This model follows simple form of polynomial model by just omitting the second invariant of the left Cauchy Green tensor (Peeters and Kussner, 1999), by doing this, U becomes:

$\mathrm{U}=\sum_{\mathrm{i}=1}^{\mathrm{N}} \mathrm{C}_{\mathrm{i} 0}\left(\overline{\mathrm{I}}_{1}-3\right)^{\mathrm{i}}+\sum_{\mathrm{i}=1}^{\mathrm{N}} \frac{1}{\mathrm{D}_{\mathrm{i}}}\left(\mathrm{J}_{\mathrm{el}}-1\right)^{2 \mathrm{i}}$

where, $\mathrm{j}$ is always zero.

Ogden model: This model proposes the strain energy function based on the principal stretches $\left(\lambda_{1}, \lambda_{2}, \lambda_{3}\right)$ for incompressible materials that is assumed $\lambda_{1} \lambda_{2} \lambda_{3}=1$. The principal stretches are directly measurable quantities and it is one obvious advantage of using them (Chang et al., 1991).

The relation of the Ogden strain energy potential is given by:

$\mathrm{U}=\sum_{\mathrm{i}=1}^{\mathrm{N}} \frac{2 \mu_{\mathrm{i}}}{\alpha_{\mathrm{i}}{ }^{2}}\left(\bar{\lambda}_{1}^{\alpha_{\mathrm{i}}}+\bar{\lambda}_{2}^{\alpha_{\mathrm{i}}}+\bar{\lambda}_{3}^{\alpha_{\mathrm{i}}}-3\right)+\sum_{\mathrm{i}=1}^{\mathrm{N}} \frac{1}{\mathrm{D}_{\mathrm{i}}}\left(\mathrm{J}_{\mathrm{el}}-1\right)^{2 \mathrm{i}}$

Where:

$\bar{\lambda}_{\mathrm{i}}=\mathrm{J}^{\frac{-1}{3}} \lambda_{\mathrm{i}}$

$\mathrm{J}=\lambda_{1} \lambda_{2} \lambda_{3}$

$\lambda_{\mathrm{i}}=$ The principal stretches

$\mathrm{J}=$ The Jacobean determinant

$\mathrm{J}_{\mathrm{el}}=$ The elastic volume ratio

The constants $\mu_{\mathrm{i}}$ and $\alpha_{\mathrm{i}}$ describe the shear behavior of the material and $\mathrm{D}_{\mathrm{i}}$ the compressibility.

The calculation of the invariant derivatives of the Ogden's energy function is more used and computationally intensive than of the polynomial form (Forni et al., 1999). This model can be more accurate in fitting experimental, when data from multiple experimental tests are available (Korochkina et al., 2005).

Mooney-Rivlin model: Strain energy potential is proposed:

$\mathrm{U}=\sum_{\mathrm{i}, \mathrm{j}=0}^{\mathrm{N}} \mathrm{C}_{\mathrm{ij}}\left(\overline{\mathrm{I}}_{1}-3\right)^{\mathrm{i}}\left(\overline{\mathrm{I}}_{2}-3\right)^{\mathrm{j}}+\sum_{\mathrm{i}=1}^{\mathrm{N}} \frac{1}{\mathrm{D}_{\mathrm{i}}}\left(\mathrm{J}_{\mathrm{el}}-1\right)^{2 \mathrm{i}}$

where, $\mathrm{C}_{\mathrm{ij}}$ are material parameter and $\mathrm{C}_{00}=0$ (Markmann and Verron, 2006). The first order for incompressible materials is presented as follows: 
$\mathrm{U}=\mathrm{C}_{10}\left(\overline{\mathrm{I}}_{1}-3\right)+\mathrm{C}_{01}\left(\overline{\mathrm{I}}_{2}-3\right)$

By setting $\mathrm{N}=0, \alpha_{1}=0$ and $\alpha_{2}=-2$ in the Ogden model, the Mooney-Rivlin model is obtained as follows (Sasso et al., 2008; Toth et al., 2005):

$\mathrm{U}=\frac{\mu_{1}}{2}\left(\bar{\lambda}_{1}^{2}+\bar{\lambda}_{2}^{2}+\bar{\lambda}_{3}^{2}-3\right)-\frac{\mu_{2}}{2}\left(\bar{\lambda}_{1}^{-2}+\bar{\lambda}_{2}^{-2}+\bar{\lambda}_{3}^{-2}-3\right)$

where, $\mathrm{C}_{10}=\frac{\mu_{1}}{2}$ and $\mathrm{C}_{01}=-\frac{\mu_{2}}{2}$.

The most favorite ones of constitutive models are Mooney-Rivlin and Ogden models. Their disadvantage is that the material parameters must be obtained by experiments and they are not physically-based parameters. The fitting method can be complicated if the number of parameters is large ( $\mathrm{Bol}$ and Reese, 2003).

Neo-Hookean model: This model is pre-programmed into ABAQUS package. If $\mathrm{N}=1$, the reduced Polynomial Model change to neo-Hookean Model:

$$
\mathrm{W}=\mathrm{C}_{10}\left(\overline{\mathrm{I}}_{1}-3\right)+\frac{1}{\mathrm{D}_{1}}\left(\mathrm{~J}_{\mathrm{el}}-1\right)^{2}
$$

This model is offered only in terms of the first deviatoric invariant (Timbrell et al., 2003). By setting $\mathrm{N}=1, \alpha_{1}=2$ in the Ogden model, the neo-Hookean can be offered (Bol and Reese, 2003):

$$
\mathrm{U}=\frac{\mu_{1}}{2}\left(\bar{\lambda}_{1}^{2}+\bar{\lambda}_{2}^{2}+\bar{\lambda}_{3}^{2}-3\right)=\mathrm{C}_{10}\left(\mathrm{I}_{1}-3\right)
$$

with the constant, $\mathrm{C}_{10}=\frac{\mu_{1}}{2}$.

And also this model is the simplest hyperelastic model for elastomeric materials when material data is insufficient. The significance of this model is because of the statistical theory of rubber elasticity appears at the strain energy function:

$$
\mathrm{W}=\frac{1}{2} \mathrm{NKT}\left(\mathrm{I}_{1}-3\right)
$$

Where:

$\mathrm{N}=$ Number of network chains per unit volume

$\mathrm{K}=$ Boltzmann's constant

$\mathrm{T}=$ The absolute temperature

Although the statistical and phenomenological begin from quite various premises, Eq. 13 is of the same form as Eq. 11 (Achenbach and Duarte, 2003).
Yeoh model: The Yeoh strain energy function is presented as following when $\mathrm{N}=3$ in the Reduced Polynomial model (Peeters and Kussner, 1999):

$$
\mathrm{U}=\sum_{\mathrm{i}=1}^{3} \mathrm{C}_{\mathrm{i} 0}\left(\overline{\mathrm{I}}_{\mathrm{I}}-3\right)^{\mathrm{i}}+\sum_{\mathrm{i}=1}^{3} \frac{1}{\mathrm{D}_{\mathrm{i}}}\left(\mathrm{J}_{\mathrm{el}}-1\right)^{2 \mathrm{i}}
$$

The initial shear modulus and bulk modulus are given by:

$\mu_{0}=2 \mathrm{C}_{10}, \mathrm{~K}_{0}=\frac{2}{\mathrm{D}_{1}}$

For following reasons this model has been chosen to describe the hyperelastic properties of rubber compounds (Ghosh et al., 2003):

- Yeoh model is applicable for a much wider range of deformation

- This model is able to predict the stress-strain behavior in different deformation modes from data gained in one simple deformation mode like uniaxial extension

Arruda and Boyce model: Physical models such as Arruda and Boyce are based on an explanation of a molecular chains network. The strain energy is assumed to be equal to the sum of the strain energies of the individual chains oriented in space in randomly (Raoult et al., 2005). This model is offered as below:

$\mathrm{U}=\mu \sum_{\mathrm{i}=1}^{5} \frac{\mathrm{C}_{\mathrm{i}}}{\lambda_{\mathrm{m}}{ }^{2 \mathrm{i}-2}}\left(\overline{\mathrm{I}}_{1}^{\mathrm{i}}-3^{\mathrm{i}}\right)+\frac{1}{\mathrm{D}}\left[\frac{\mathrm{J}_{\mathrm{el}}{ }^{2}-1}{2}-\operatorname{Ln}\left(\mathrm{J}_{\mathrm{el}}\right)\right]$

With:

$\mathrm{C}_{1}=\frac{1}{2}, \mathrm{C}_{2}=\frac{1}{20}, \mathrm{C}_{3}=\frac{11}{1050}, \mathrm{C}_{4}=\frac{19}{7000}, \mathrm{C}_{5}=\frac{519}{673750}(17)$

$\mu=$ The initial shear modulus

$\lambda_{m}=$ The locking stretch, at which the upturn of the stress-strain curve would rise significantly

$\mathrm{D}=$ Double the inverse bulk modulus at small strain; i.e.:

$\mathrm{D}=\frac{2}{\mathrm{~K}}$

where, D is set to zero for incompressible material (Seibert and Schoche, 2000).

This model, in the range of smaller strains, helps to make accurate solutions with neglecting the second 
invariant of the left Cauchy-Green tensor. With increasing locking stretch parameter, a sufficient accuracy in both small and large strain is obtained (Seibert and Schoche, 2000).

Strain energy function is independent of the second stretch invariant for several hyperelastic constitutive models such as the neo-Hookean model, the Yeoh model and the Arruda-Boyce model (Sharma, 2003). Each of these models has a set of mathematical form with different parameters that are established by using algorithm based curve-fitting of experimental data. If the strain energy density is supposed to be independent of the second invariant, a single test such as a uniaxial tension test is needed for material response. As a result, it can not present closely the behavior in other modes as a multi-parameter model but it will present a reasonable approximation and is easier to use (Marlow, 2003).

Van der Waals model: This model is known as the Kilian model and introduced as follows (Seibert and Schoche, 2000):

$$
\begin{aligned}
U= & \mu\left\{-\left(\lambda_{\mathrm{m}}^{2}-3\right)[\operatorname{Ln}(1-\eta)+\eta]-\frac{2}{3} \mathrm{a}\left(\frac{\tilde{\mathrm{I}}-3}{2}\right)^{\frac{3}{2}}\right\} \\
& +\frac{1}{\mathrm{D}}\left(\frac{\mathrm{J}^{2}-1}{2}-\operatorname{Ln}(\mathrm{J})\right)
\end{aligned}
$$
in:

With $\beta$ representing the linear mixture parameter

$$
\tilde{\mathrm{I}}=(1-\beta) \mathrm{I}_{1}+\beta \tilde{\mathrm{I}}_{2} \text { and } \eta=\sqrt{\frac{\tilde{\mathrm{I}}-3}{\lambda_{\mathrm{m}}^{2}-3}}
$$

It uses two invariants of the left deviatoric Cauchy Green tensor in I. If $\beta=0$, only the effects of the first invariant are considered and if there is only one type of test data, this parameter is recommended to be set to zero. The interaction parameter $\alpha$ is difficult to measure. It is usually between 0.1 and 0.3 . The formula of this model cannot be used, when the deformation of the material makes stretches larger than the locking stretch $\lambda_{\mathrm{m}}$ (Peeters and Kussner, 1999).

Fitting experimental data to hyperelastic models: Hyperelastic models are widely used in the Finite Element Analysis (FEA) programs. A relation between stress and strain is required for the FEA of rubber materials. The material parameters in the strain energy potential can be determined by the fitting of the strain energy function to stress-strain data based on a non- linear least square optimization method. The optimization process is used in software to minimize the error with respect to the model's parameter. There are various algebraic forms to curve fit the dependence of the strain energy based on the invariants and the principal stretches. The strain energy density parameters have been fitted on experimental data from tensile, compression, pure shear. Then, hyperelastic models coefficients will obtain to provide a good fit between the predictions from the model and stressstrain data. In most cases, the uniaxial test data have been used to obtain the coefficients of the strain energy function. However, it requires a great deal of effort to take a curve fitting with good accuracy. The material parameters can be assessed in terms of their ability to match the stress-strain data over a large range of deformations. It should be noted that fitting results should always be checked in curve fitting approach with the recommended strategies such as using a different model and providing more data points. However, models with few material parameters are preferred for the purpose of computational efficiency (Meunier et al., 2008; Ogden et al., 2004; Wang et al., 2002; 2008; Li et al., 2009; Zhao et al., 2008; Mahmoud et al., 2007; Zine et al., 2006 Liechti et al., 1989; Murphy, 2000; Subhani and Kumar, 2009; Choi et al., 2005; Shangguan and Lu, 2004; Woo and Kim, 2006; Avanzini, 2005; Liang and Chandrashekhara, 2008; Chui et al., 2004; Wissler and Mazza, 2005).

\section{CONCLUSION}

Rubber-like material can be explained by continuum based mechanical models. Research on accurate constitutive modeling has presented several models describing the elastic energy as a function of the deformation. The models are based on strain invariant or stretch ratio. Conventional hyperelastic material models such as the Mooney-Rivlin or Ogden model operate very well for many applications. MooneyRivlin polynomial and Ogden theoretically provide, the same results. However there is a difference between the methods in terms of their formula. Mooney-Rivlin model present the strain energy density based on the principal strain invariants, whereas, Ogden model offer the strain energy density based on three principal stretches. And also, Mooney-Rivlin and neo-Hookean are as special case of this model. Generally, classification of the models is presented based on domain of validity for all modes of deformation, the number of parameters and the type of formulation used to derive the models. So that, it depends on the 
considered domain of deformation, for example the neo-Hookean model, the Mooney model and the Ogden model can be used for small, moderate and large strain, respectively.

\section{REFERENCES}

Abraham, F., T. Alshuth and S. Jerrams, 2005. The effect of minimum stress and stress amplitude on the fatigue life of non strain crystallizing elastomers. Mater. Des., 26: 239-245. DOI: 10.1016/j.matdes.2004.02.020

Achenbach, M. and J. Duarte, 2003. A Finite Element Methodology to Predict Age-Related Mechanical Properties and Performance Changes in Rubber Components. In: Constitutive models for rubber III, Busfield, J. (Ed.). AA Balkema Publishers, UK., ISBN: 10: 9058095665, pp: 59-67.

Amin, A.F.M.S., M.S. Alam and Y. Okui, 2002. An improved hyperelasticity relation in modeling viscoelasticity response of natural and high damping rubbers in compression: Experiments, parameter identification and numerical verification. Mech. Mater. $\quad 34$ 75-95. http://cat.inist.fr/?aModele $=$ afficheN\&cpsidt $=1350$ 8757

Avanzini, A., 2005. Mechanical characterization and modeling of polymeric materials for high-pressure sealing. Exp. Mech., 45: 53-64. http://cat.inist.fr/?aModele $=$ afficheN\&cpsidt $=1677$ 0527

Beatty, M.F., 2003. An average-stretch full-network model for rubber elasticity. J. Elast., 70: 65-86. DOI: 10.1023/B:ELAS.0000005553.38563.91

Bol, M. and S. Reese, 2003. Finite Element Modeling of Polymer Networks Based on Chain Statistics. In: Constitutive Models for Rubber III, Busfield, J. (Ed.). AA Balkema Publishers, UK., ISBN: 10: 9058095665, pp: 203-211

Boyce, M.C. and E.M. Arruda, 2000. Constitutive models of rubber elasticity: A review. Rubber Chem. Technol., 73: 504-523. http://cat.inist.fr/?aModele $=$ afficheN\&cpsidt $=1528883$

Chagnon, G., G. Marckmann and E. Verron, 2004. A comparison of the Hart-Smith model with ArrudaBoyce and gent formulations for rubber elasticity. Rubber Chem. Technol., 77: 724-735. http://cat.inist.fr/?aModele $=$ afficheN $\&$ cpsidt $=16233017$

Chang, T.Y.P., A.F. Saleeb and G. Li, 1991. Large strain analysis of rubber-like materials based on a perturbed Lagrangian variational principle. Comput. Mech., 8: 221-233. http://adsabs.harvard.edu/abs/1991CompM...8..221C
Cheng, M. and W. Chen, 2003. Experimental investigation of the stress-stretch behavior of EPDM rubber with loading rate effects. Int. J. Solids $\quad$ Struct., $\quad 40: \quad 4749-4768$. http://cat.inist.fr/?aModele $=$ afficheN\&cpsidt $=1494$ 9380

Choi, J.H., H.J. Kang, H.Y. Jeong, T.S. Lee and S.J. Yoon, 2005. Heat aging effects on the material property and the fatigue life of vulcanized natural rubber and fatigue life prediction equations. J. Mech. Sci. Technol., 19: 1229-1242. http://cat.inist.fr/?aModele $=$ afficheN\&cpsidt $=1685$ 8157

Chui, C., E. Kobayashi, X. Chen, T. Hisada and I. Sakuma, 2004. Combined compression and elongation experiments and non-linear modeling of liver tissue for surgical simulation. Med. Biol. Eng. Comput., 42: 787-798. DOI: 10.1007/BF02345212

Coran, A.Y., 2006. Elastomers. In: Handbook of Plastics Technologies, Harper, C. (Ed.), 2nd Edn., McGraw-Hill Companies, New York, ISBN: 10: 0071460683, pp: 4.1-4.111.

Dorfmann, A. and R.W. Ogden, 2004. A constitutive model for the Mullins effect with permanent set in particle-reinforced rubber. Int. J. Solids Struct., 41: $1855-1878$.

http://cat.inist.fr/?aModele $=$ afficheN\&cpsidt $=15489653$

Forni, M., A. Martelli and A. Dusi, 1999. Implementation and Validation of Hyperelastic Finite Element Models of High Damping Rubber Bearings. In: Constitutive models for Rubber, Al Dorfmann, (Ed.). AA Balkema Publishers, UK., ISBN: 10: 9058091139, pp: 237-247.

Garcia Ruiz, M.J. and L.Y. Suarez Gonzalez, 2006. Comparison of hyperelastic material models in the analysis of fabrics. Int. J. Cloth. Sci. Tech., 18: 314-325. DOI: 10.1108/09556220610685249

Gent, A.N., 1992. Elasticity. In: Engineering with Rubber, Gent, A.N. (Ed.). Hanser Publishers, New York, ISBN: 0-07-743789-2, pp: 33-66.

Ghosh, P., A. Saha and R. Mukhopadhyay, 2003. Prediction of tyre Rolling Resistance Using FEA. In: Constitutive Models for Rubber III, Busfield, J. (Ed.). AA Balkema Publishers, UK., ISBN: 10: 9058095665, pp: 141-145.

Guo, Z. and L.J. Sluys, 2006. Application of a new constitutive model for the description of rubberlike materials under monotonic loading. Int. J. Solids $\quad$ Struct., $\quad 43$ : 2799-2819. http://cat.inist.fr/?aModele $=$ afficheN\&cpsidt $=17601790$

Hertz, D. L., 1992. Introduction. In: Engineering with Rubber, Gent, A.N. (Ed.), Hanser Publishers, New York, ISBN: 0-03-046788-7, pp: 1-9. 
Horgan, C.O. and G. Saccomandi, 1999. Simple torsion of isotropic, hyperelastic, incompressible materials with limiting chain extensibility. J. Elasticity., 56: 159-170. DOI: 10.1023/A:1007606909163

Horgan, C.O. and G. Saccomandi, 2003. Finite thermoelasticity with limiting chain extensibility. J. Mech. Phys. Solids, 51: 1127-1146. DOI: 10.1016/S0022-5096(02)00144-8

Horgan, C.O., R.W. Ogden and G. Saccomandi, 2004. A theory of stress softening of elastomers based on finite chain extensibility. Proc. R. Soc. Lond. A, 460: $1737-1754$.

http://rspa.royalsocietypublishing.org/content/460/ 2046/1737.abstract

Kaliske, M., L. Nasdala and H. Rothert, 2001. On damage modeling for elastic and viscoelastic materials at large strain. Comput. Struct., 79: 21332141. DOI: 10.1016/S0045-7949(01)00061-X

Korochkina, T.V., T.C. Claypole and D.T. Gethin, 2005. Choosing Constitutive Models for Elastomers used in Printing Processes. In: Constitutive models for Rubber IV, Austrell, P.E. and L. Kari (Eds.). AA Balkema Publishers, UK., ISBN: 10: 0415383463, pp: 431-435.

Lemaitre, J., 2001. Background on Modeling. In: Handbook of Materials Behavior Models, Lemaitre, J. (Ed.). Academic Press, USA., ISBN: 10: 0124433413, pp: 3-14.

Li, Q., J. Zhao and B. Zhao, 2009. Fatigue life prediction of a rubber mount based on test of material properties and finite element analysis. Eng. Fail. Anal., 16: 2304-2310. DOI: 10.1016/J.ENGFAILANAL.2009.03.008

Liechti, K.M., E.B. Becker, C. Lin and T.H. Miller, 1989. A fracture analysis of cathodic delamination in rubber to metal bonds. Int. J. Fract., 39: 217-234. DOI: $10.1007 / \mathrm{BF} 00047451$

Liang, G. and K. Chandrashekhara, 2008. Neural network based constitutive model for elastomeric foams. Eng. Struct., 30: 2002-2011. DOI: 10.1016/j.engstruct.2007.12.021

Mahmoud, W.E., S.A. Mansour, M. Hafez and M.A. Salam, 2007. On the degradation and stability of High Abrasion Furnace black (HAF)/acrylonitrile butadiene rubber (NBR) and High Abrasion Furnace black (HAF)/graphite/acrylonitrile butadiene rubber (NBR) under cyclic stress-strain. Polymer Degrad. Stab., 92: 2011-2015. DOI: 10.1016/J.POLYMDEGRADSTAB.2007.08.005

Mars, W.V., 2002. Cracking energy density as a predictor of fatigue life under multiaxial conditions. Rubber Chem. Technol., 75: 1-17. http://cat.inist.fr/?aModele $=$ afficheN\&cpsidt $=13807073$
Mars, W.V. and A. Fatemi, 2004. Observations of the constitutive response and characterization of filled natural rubber under monotonic and cyclic multiaxial stress states. J. Eng. Mater. Technol., 126: 19-28.

http://cat.inist.fr/?aModele $=$ afficheN\&cpsidt $=1549$ 7586

Markmann, G. and E. Verron, 2005. Efficiency of Hyperelastic Models for Rubber-Like Materials. In: Constitutive Models for Rubber IV, Austrell, P.E. and L. Kari (Eds.). AA Balkema Publishers, UK., ISBN: 10: 0415383463, pp: 375-380

Markmann, G. and E. Verron, 2006. Comparison of hyperelastic models for rubber-like materials. Rubber Chem. Technol., 79: 835-858. http://imechanica.org/node/1896

Marlow, R.S., 2003. A General First-Invariant Hyperelastic Constitutive Model. In: Constitutive Models for Rubber III, Busfield, J. (Ed.). AA Balkema Publishers, UK., ISBN: 10: 9058095665,pp: 157-160.

Meunier, L., G. Chagnon, D. Favier, L. Orge and P. Vacher, 2008. Mechanical experimental characterisation and numerical modeling of an unfilled silicone rubber. Polymer Test., 27: 765-777. DOI: 10.1016/j.polymertesting.2008.05.011

Muhr, A.H., 2005. Modeling the stress-strain behavior of rubber. Rubber Chem. Technol., 78: 391-425. http://cat.inist.fr/?aModele $=$ afficheN\&cpsidt $=1714$ 0929

Murphy, J.G., 2000. Strain energy functions for a Poisson power law function in simple tension of compressible hyperelastic materials. J. Elasticity, 60: 151-164. DOI: 10.1023/A:1010843015909

Nagdi, K., 1993. Rubber as an Engineering Material. Hanser Publisher, Munich, Germany, ISBN: 0-06056388-9, pp: 502.

Naser, B., M. Kaliske and M. Andre, 2005. Durability Simulations of Elastomeric Structures. In: Constitutive Models for Rubber IV, Austrell, P.E. and L. Kari (Eds.). AA Balkema Publishers, UK., ISBN: 10: 0415383463, pp: 45-50.

Ogden, R.W., 1972. Large deformation isotropic elasticity-on the correlation of theory and experiment for incompressible rubberlike solids. Proc. R. Soc. Lond. A, 326: 565-584. http://rspa.royalsocietypublishing.org/content/328/ 1575/567.short

Ogden, R.W., G. Saccomandi and I. Sgura, 2004. Fitting hyperelastic models to experimental data. Comput. Mech., 34: 484-502. DOI: 10.1007/s00466-004-0593-y 
Peeters, F.J.H. and M. Kussner, 1999. Material Law Selection in the Finite Element Simulation of Rubber-like Materials and its Practical Application in the Industrial Design Process. In: Constitutive Models for Rubber, Al Dorfmann (Ed.). AA Balkema Publishers, UK., ISBN: 10: 9058091139 , pp: 29-36.

Pucci, E. and G. Saccomandi, 2002. A note on the Gent model for rubber-like materials. Rubber Chem. Technol., 75: 839-851. http://cat.inist.fr/?aModele $=$ afficheN $\&$ cpsidt $=1453$ 3638

Raoult, I., C. Stolz and M. Bourgeois, 2005. A Constitutive Model for the Fatigue Life Prediction of Rubber. In: Constitutive Models for Rubber IV, Austrell, P.E. and L. Kari (Eds.). AA Balkema Publishers, UK., ISBN: 10: 0415383463, pp: 129-134.

Sasso, M., G. Palmieri, G. Chiappini and D. Amodio, 2008. Characterization of hyperelastic rubber-like materials by biaxial and uniaxial stretching tests based on optical methods. Polymer Test., 27: 995-1004. DOI: 0.1016/J.POLYMERTESTING.2008.09.001

Seibert, D.J. and N. Schoche, 2000. Direct comparison of some recent rubber elasticity models. Rubber Chem. Technol., 73: 366-384. http://cat.inist.fr/?aModele $=$ afficheN\&cpsidt $=1457$ 477

Selvadurai, A.P.S., 2006. Deflections of a rubber membrane. J. Mech. Phys. Solids, 54: 1093-1119. DOI: $10.1016 /$ J.JMPS.2006.01.001

Sharma, S., 2003. Critical Comparison of Popular Hyper-Elastic Material Models in Design of AntiVibration Mounts for Automotive Industry Through FEA. In: Constitutive Models for Rubber III, Busfield, J. (Ed.).AA Balkema Publishers, UK., ISBN: 10: 9058095665, pp: 161-167.

Shangguan, W.B. and Z.H. Lu, 2004. Experimental study and simulation of a hydraulic engine mount with fully coupled fluid-structure interaction finite element analysis model. Comput. Struct., 82: 1751-1771. http://cat.inist.fr/?aModele $=$ afficheN\&cpsidt $=16019118$

Smith, L.P., 1993. The Language of Rubber: An Introduction to the Specification and Testing of Elastomers. Butterworth-Heinemann Ltd., London, England, ISBN: 10: 0750614137, pp: 257.

Subhani, P.M. and R.K. Kumar, 2009. A new stored energy function for rubber like materials for low strains. Mech. Adv. Mater. Struct., 16: 402-416. DOI: $10.1080 / 15376490902781167$

Toth, B.K., G. Faffai and I. Bojtar, 2005. Analysis of the mechanical parameters of human brain aneurysm. Acta Bioeng. Biomech., 7: 3-23. http://www.actabio.pwr.wroc.pl/Vol7No1/1.pdf
Timbrell, C., M. Wiehahn, G. Cook and A.H. Muhr, 2003. Simulation of Crack Propagation in Rubber. In: Constitutive Models for Rubber III, Busfield, J. (Ed.). A.A. Balkema Publishers, UK., pp: 11-20.

Wang, B., H. Lu and G. Kim, 2002. A damage model for the fatigue life of elastomeric materials. Mech. Mater., 34: 475-483. DOI: 10.1016/S01676636(02)00175-8

Wang, Y., W. Yu, X. Chen and L. Yan, 2008. Fatigue life prediction of vulcanized natural rubber under proportional and non-proportional loading. Fatigue Fract. Eng. Mater. Struct., 31: 38-48. http://cat.inist.fr/?aModele $=$ afficheN\&cpsidt $=2003$ 1292

Whibley, I.J., E. Cutts, M. Philllip and D. Pearce, 2005. Mechanical Characterization and Modeling of Elastomers Based On Chemical Composition. In: Constitutive Models for Rubber IV, Austrell, P.E. and L. Kari (Eds.). AA Balkema Publishers, UK., ISBN: 10: 0415383463, pp: 437-441.

Wissler, M. and E. Mazza, 2005. Modeling and simulation of dielectric elastomer actuators. Smart Mater. Struct., 14: 1396-1402. DOI: 10.1088/0964$1726 / 14 / 6 / 032$

Woo, C.S. and W.D. Kim, 2006. Heat-aging effects on the material properties and fatigue life prediction of vulcanized natural rubber. e-J. Soft Mater., 2: 7-12. http://www.jstage.jst.go.jp/article/ejsm/2/0/2_7/_article

Yan, J. and J.S. Strenkowski, 2005. An Experimental Study of Rubber Cutting Process. In: Constitutive Models for Rubber IV, Austrell, P.E. and L. Kari (Eds.). AA Balkema Publishers, UK., ISBN: 10: 0415383463, pp: 97-102.

Yan, J. and J.S. Strenskowski, 2006. A finite element analysis of orthogonal rubber cutting. J. Mat. Process. Tech. 174: 102-108. DOI: 10.1016/j.jmatprotec.2005.02.265

Yeoh, O.H. and P.D. Fleming, 1997. A new attempt to reconcile the statistical and phenomenological theories of rubber elasticity. J. Polymer Sci. Part B, 35:

1919-1931. http://cat.inist.fr/?aModele=afficheN\&cpsidt=2759 526

Zine, A., N. Benseddiq, M.N. Abdelaziz, N.A. Hocine and D. Bouami, 2006. Prediction of rubber fatigue life under multiaxial loading. Fatigue Fract. Eng. Mater. $\quad$ Struct. $\quad 29$ : 267-278. http://cat.inist.fr/?aModele $=$ afficheN\&cpsidt $=17532829$

Zhao, J., Q. Li and X. Shen, 2008. Finite element analysis and structure optimization for improving the fatigue life of rubber mounts. J. Macromol. Sci. Part A, 45: 479-484. DOI: $10.1080 / 10601320801977780$ 